*Manuscrip屯Fixilepreprint doi: https://doi.org/10.1101/2020.05.28.117739; this version posted May 29, 2020. The copyright holder for this preprint (which Click here to was Wot fertified RePefereview) is the author/funder, who has granted bioRxiv a license to display the preprint in perpetuity. It is made

1

2

3

\title{
Deterioration of Glutaraldehyde Crosslinked Heterograft Biomaterials due to Advanced Glycation End Product Formation and Serum Albumin Infiltration
}

Christopher A. Rock ${ }^{a}$, Samuel Keeney ${ }^{\mathrm{a}}$, Andrey Zakharchenko ${ }^{\mathrm{a}}$, Hajime Takano ${ }^{\mathrm{b}}$, David A. Spiegel ${ }^{\mathrm{c}}$, Abba M. Krieger $^{\mathrm{d}}$, Giovanni Ferrari ${ }^{\mathrm{e}}$, Robert J. Levy ${ }^{\text {a\# }}$

aDivision of Cardiology, Department of Pediatrics, The Children's Hospital of Philadelphia, Philadelphia, PA 19104, USA

bivision of Neurology, Department of Pediatrics, The Children's Hospital of Philadelphia, Philadelphia, PA 19104, USA

${ }^{c}$ Department of Chemistry, Yale University, New Haven, CT, 06520, USA

${ }^{\mathrm{d}}$ Department of Statistics, The Wharton School, University of Pennsylvania, Philadelphia, PA, 19104, USA

${ }^{\mathrm{e}}$ Departments of Surgery and Biomedical Engineering, Columbia University, New York, NY, 10032 USA

Contact for corresponding author :

Robert J. Levy, MD

Division of Cardiology, Department of Pediatrics

The Children's Hospital of Philadelphia

3615 Civic Center Blvd

Philadelphia, PA 19104

Phone: 215590 4788; Fax: 215590 5454; Email: levyr@email.chop.edu

$\underline{\text { Key words: }}$

Collagen structure

Biomechanics

Structural valve degeneration

Glucose

Glyoxal 


\section{ABSTRACT}

Bioprosthetic heart valves (BHV) are fabricated from glutaraldehyde cross-linked heterograft tissue, such as bovine pericardium (BP) or porcine aortic valves. BHV develop structural valve degeneration (SVD), often with calcification, requiring BHV replacement. Advanced glycation end products (AGE) are post-translational, nonenzymatic carbohydrate protein modifications. AGE are present in SVD-BHV clinical explants and not detectable in unimplanted BHV. Here, we studied the hypothesis that BHV susceptibility to AGE formation and serum protein infiltration results in deterioration of both leaflet collagen structure and mechanical properties. In vitro experiments studied BP and porcine collagen sponges (CS) for susceptibility to AGE formation using ${ }^{14} \mathrm{C}$-glucose and ${ }^{14} \mathrm{C}$-glyoxal with and without bovine serum albumin (BSA), as a model serum protein. The results showed AGE formation is a rapid and progressive process. BSA co-incubations reduced glyoxal and glucose uptake by BP and CS. Incubating BP in BSA caused a substantial increase in BP mass, enhanced by glyoxal co-incubation. Per two-photon microscopy, BP with AGE formation and BSA infiltration each induced significant disruption in collagen microarchitecture, with loss of collagen alignment and crimp. These effects are cumulative with the greatest disruption occurring when there was both AGE formation and BSA infiltration. Uniaxial testing of CS demonstrated that AGE formation, together with BSA uptake compared to controls, caused a significant deterioration in mechanical properties with a loss of viscoelastic relaxation and increased stiffness. It is concluded that AGE-BSA associated collagen structural disruption and deterioration of mechanical properties contribute to SVD. 


\section{INTRODUCTION}

Heart valve disease is a worldwide problem, affecting millions[1]. At present, there is no effective medical therapy. Patients requiring treatment must undergo either attempted repair of the diseased valves or replacement with a prosthesis. The current preferred replacement valves in adults are bioprosthetic heart valves (BHV) fabricated from glutaraldehyde-fixed xenografts, fabricated from either bovine pericardium (BP) or porcine aortic valves[1]. BHV are relatively non-thrombogenic compared to mechanical heart valve prostheses; this reduces the need for anti-coagulants[2]. However, BHV functional lifespans are limited due to the progressive development of structural valve degeneration (SVD), most often involving leaflet calcification[3,4]. Much of the prior research concerned with mitigating SVD focused on the inhibition of calcification as the primary mechanism[5-9]. However, this yielded only incremental improvements in BHV lifespan[10-13]. Prior studies of explanted BHV showed that the degree of calcification does not completely explain SVD, and that approximately $25 \%$ of failed valves lack any significant calcification[14].

The present studies investigated the hypothesis that advanced glycation end products (AGE) contribute to the pathophysiology of SVD. AGE result from the post-translational, non-enzymatic modification of proteins by hexoses or hexose breakdown products from Amadori reactions or other oxidative related mechanisms[15-17]. AGE both modify proteins involved in normal physiologic functions, such as serum albumin and hemoglobin (HA1C) and are associated with the pathophysiology of a number of important diseases including diabetes[18,19] and Alzheimer's Disease[20-22]. The importance of AGE for SVD is incompletely understood. A prior study by our group evaluated a clinical cohort of 45 explanted BHV with SVD and demonstrated via immunohistochemistry (IHC) that AGE and human serum albumin were present in all explants but were undetectable in unimplanted BHV[23]. This BHV explant study was complemented by ex vivo pulse duplicator experiments demonstrating that exposure to both glyoxal, a common AGE intermediary, and serum albumin significantly impaired the hydrodynamic performance of trileaflet, clinical grade BHV[23].

The present studies investigated the hypothesis that BHV are highly susceptible to AGE modification due to both glucose and glyoxal addition and serum albumin uptake, and that these events disrupt the structure of BHV leaflets, adversely affecting biomechanical performance. To test this hypothesis, experiments were performed to determine the following: the glycation kinetics of BHV tissues, the effects of glutaraldehyde-fixation on glycation, the impact of serum albumin exposure on glycation, glycation's capacity to alter BHV collagen microarchitecture, and glycation's capacity to alter glutaraldehyde-fixed collagen's linear elastic and viscoelastic properties.

\section{MATERIALS AND METHODS}

\subsection{Materials}

Bovine serum albumin (BSA, protease-free, $>98 \%$ purity), D-glucose, glyoxal, sodium azide, sodium chloride, sodium borohydride, and HEPES were purchased from Sigma-Aldrich (St. Louis, MO). Fresh BP were shipped on ice from Animal Technologies (Tyler, TX). Surgifoam ${ }^{\circledR}$ hemostatic collagen sponges (CS) composed of gelatin purified from porcine skin were purchased from Ethicon (Somerville, NJ). The ${ }^{14} \mathrm{C}$-radiolabeled D-glucose $(5 \mathrm{mCi} / \mathrm{mmol})$ and glyoxal $(110 \mathrm{mCi} / \mathrm{mmol})$ were purchased from American Radiolabeled Chemicals (St. Louis, MO). Biosol and Bioscint were purchased from National Diagnostics (Atlanta, GA). All other sources of materials have been indicated in individual methods.

\subsection{Glutaraldehyde Fixation of Bovine Pericardium and Collagen Sponges}

$\mathrm{BP}$ in a fresh state, shipped on ice, were rinsed in saline $(0.9 \% \mathrm{NaCl})$ and any residual fatty or muscular tissue was removed by dissection. The BP and CS were immersed for 7 days at room temperature $0.6 \%$ glutaraldehyde 
(Polysciences Inc.; Warrington, PA) in HEPES buffer solution (50mM HEPES, 0.9\% NaCl, pH 7.4). The samples were then rinsed in fresh HEPES buffer solution for 1 hour before transferring to storage solution of $0.2 \%$ glutaraldehyde in HEPES buffer solution and stored at $4{ }^{\circ} \mathrm{C}$. Prior to any experiments, samples were exhaustively rinsed with phosphate-buffered saline (PBS) to remove the storage solution.

\subsection{Radiolabeled Glycation Assays}

\subsubsection{Glycation of Glutaraldehyde Fixed Collagenous Tissues}

To quantify the glycation kinetics of the model substrates, samples ( $\mathrm{n}=10$ for BP and $\mathrm{n}=5$ for CS) were punched from glutaraldehyde-fixed BP and CS using an 8mm biopsy punch. These samples were incubated for 1, 3, 7, 14, or 28 days at $37^{\circ} \mathrm{C}$ shaking at $110 \mathrm{RPM}$ in solutions ( $1 \mathrm{ml}$ per sample) of PBS with either: glucose $(100 \mathrm{mM})$, glucose $(100 \mathrm{mM})+$ BSA $(5 \%)$, glyoxal $(50 \mathrm{mM})$, or glyoxal $(50 \mathrm{mM})+$ BSA $(5 \%)$. All incubations contained sodium azide $(0.1 \%)$ to maintain sterility. The glucose media contained ${ }^{14} \mathrm{C}$-labeled glucose $(0.544 \mu \mathrm{Ci} / \mathrm{ml})$. The glyoxal media contained ${ }^{14} \mathrm{C}$-labeled glyoxal $(0.356 \mu \mathrm{Ci} / \mathrm{ml})$. The radioactivity of each medium was measured using a Beckman LS 6000 (Beckman Coulter; Brea, CA). Following incubations, the samples were extensively rinsed with deionized water and lyophilized for at least 48 hours. The dried samples were weighed and then digested using Biosol and combined with Bioscint for scintillation counting. The scintillation count was used to calculate glucose or glyoxal incorporation into the substrate normalized by dry weight.

\subsubsection{Glycation Comparison of Fresh and Fixed Bovine Pericardium}

To compare the glycation capacity of fresh BP relative to glutaraldehyde-fixed BP, samples $(n=5)$ were punched from fresh BP and glutaraldehyde-fixed BP using an 8mm biopsy punch. Samples were rinsed with PBS and then incubated for 28 days in PBS with either: glucose $(100 \mathrm{mM})$, glucose $(100 \mathrm{mM})+$ BSA $(5 \%)$, glyoxal $(50 \mathrm{mM})$, or glyoxal $(50 \mathrm{mM})+$ BSA $(5 \%)$. Sterility was maintained by adding sodium azide $(0.1 \%)$ to each incubation. Prior to incubation, radiolabeled reagents were added as above. To calibrate the radioactive signal and confirm sufficient excess of radioactive reagents, a $500 \mu 1$ aliquot was taken from each incubation medium at the start and end of incubation, and radioactivity levels determined. To measure each aliquot's radioactivity, each aliquot had $5 \mathrm{ml}$ of Bioscint added, was shaken till the solution turned clear, and then underwent scintillation counting. At the conclusion of the incubations, samples were exhaustively rinsed with deionized water and underwent a minimum of 48 hours of lyophilization. The lyophilized samples were weighed and then digested in Biosol as above.

\subsubsection{Glycation Kinetics of Bovine Serum Albumin}

To study the glycation kinetics of albumin in vitro, BSA (5\%) was incubated with either glucose (100mM) or glyoxal $(50 \mathrm{mM})$ for 28 days at $37^{\circ} \mathrm{C}$ shaking at $110 \mathrm{RPM}$. The solutions contained either ${ }^{14} \mathrm{C}$-labeled glucose $(0.544 \mu \mathrm{Ci} / \mathrm{ml})$ or ${ }^{14} \mathrm{C}$-labeled glyoxal $(0.356 \mu \mathrm{Ci} / \mathrm{ml})$ as above. To maintain the sterility of reaction, the mixture was passed through a $0.2 \mu \mathrm{m}$ syringe filter and sodium azide $(0.02 \%)$ was added. At 1 day, 3 days, 7 days, 14 days, and 28 days samples were taken from the reacting mixture and passed through Zeba Spin size-exclusion centrifuge columns (ThermoFisher; Waltham, MA) to separate glycated BSA from unbound glucose or glyoxal. To estimate the degree of glycation, each of triplicate samples was mixed with Biosol and measured using a liquid scintillation counter. The amount of bound glucose or glyoxal was quantitated and expressed as a molar ratio of glucose or glyoxal per mg BSA.

\subsection{Serum Albumin Uptake by Bovine Pericardium}

Serum albumin uptake kinetics were quantified by measuring the dry and wet mass change of BP samples following BSA exposure. Square samples ( $\mathrm{n}=5$, ca. $20 \mathrm{~mm}$ by $20 \mathrm{~mm},>18 \mathrm{mg}$ dry weight) were cut from glutaraldehyde-fixed BP. The samples were exhaustively rinsed in deionized water to remove any residual salts. Samples were lyophilized for at least 48 hours and their dry weight was measured. The samples were 
subsequently immersed in $5 \mathrm{ml}$ deionized water per sample for 24 hours gently shaking at $4^{\circ} \mathrm{C}$ to rehydrate. The wet weight of each sample was measured by blotting each side with Whatman paper (Maidstone, United Kingdom) to remove excess water. The samples were next incubated for 1, 3, 7, 14, or 28 days in solutions (5ml per sample) of PBS with either: BSA $(5 \%)$, BSA $(5 \%)+$ glucose $(100 \mathrm{mM})$ or BSA $(5 \%)+$ glyoxal $(50 \mathrm{mM})$. All incubations had sodium azide $(0.1 \%)$ added for sterility. Following incubations, the samples were again exhaustively rinsed with deionized water and lyophilized for 48 hours to calculate dry weight. Wet mass was recalculated as per the previous method.

\subsection{Morphological Studies}

\subsubsection{Sample preparation}

To prepare samples for immunohistochemistry (IHC) and two-photon microscopy endpoints, samples $(\mathrm{n}=5)$ were punched from glutaraldehyde-fixed BP using an 8mm biopsy punch. The BP samples were incubated for 28 days in ( $1 \mathrm{ml}$ per sample) PBS or PBS with either: BSA $(5 \%)$, glucose $(100 \mathrm{mM})$, glucose $(100 \mathrm{mM})+$ BSA $(5 \%)$, glyoxal $(50 \mathrm{mM})$, or glyoxal $(50 \mathrm{mM})+\mathrm{BSA}(5 \%)$. A group of $5 \mathrm{BP}$ samples were set aside after 24 hours of each incubation to provide a baseline samples for two-photon microscopy. Sodium azide $(0.1 \%)$ was added to maintain sterility. BP samples were then exhaustively rinsed with PBS prior to follow-up protocols.

\subsubsection{Immunohistochemistry Assays}

Tissue designated for IHC was fixed in $10 \%$ neutral buffered formalin at $4{ }^{\circ} \mathrm{C}$ for 48 hours. The tissue was then gradually dehydrated and embedded in paraffin. The paraffin blocks were sectioned at $6 \mu \mathrm{m}$ and mounted on Histobond (VWR; Radnor, PA) slides. The slides were then heated in an oven and re-hydrated in successive xylene to ethanol baths. The slides were then incubated overnight in $60^{\circ} \mathrm{C}$ citrate buffer (ThermoFisher; Waltham, MA) for antigen retrieval. Following antigen retrieval, slides were rinsed then incubated with primary antibody ( $\alpha$ AGE, $0.4 \mu \mathrm{g} / \mathrm{ml} \mid$ Abcam, Cambridge, United Kingdom; $\alpha$ CML, $0.12 \mu \mathrm{g} / \mathrm{ml} \mid$ Abcam; $\alpha$ Glucosepane, $4.5 \mu \mathrm{g} / \mathrm{ml} \mid$ David Spiegel laboratory, Yale University, New Haven, CT, per material transfer agreement; $\alpha B S A, 0.05 \mathrm{ug} / \mathrm{ml}$ Abcam) overnight at $4^{\circ} \mathrm{C}$. Samples to be stained using $\alpha$-glucosepane were first incubated overnight at room temperature with $\mathrm{NaBH}_{4}(80 \mathrm{mM})$ in order to reduce glutaraldehyde reaction products that could cross-react with the antibody [23]. Samples were then were incubated with primary antibody as previously described. After incubation with primary antibodies, slides were washed and incubated with $\mathrm{H}_{2} \mathrm{O}_{2}(3 \%)$ for 10 minutes. Slides were then rinsed and incubated for 1 hour at room temperature with the appropriate horseradish peroxidase polymer-conjugated secondary antibody (Abcam; Cambridge, United Kingdom). Slides were then rinsed and incubated for 8 minutes at room temperature with 3,3'Diaminobenzidine substrate (Abcam; Cambridge, United Kingdom). Slides were then counter-stained using regressive hematoxylin staining, dehydrated, and coverslipped.

\subsubsection{Two-photon Microscopy}

All two-photon microscopy scans were performed using a custom Prairie Technologies Ultima Multiphoton Microscopy on Olympus BX-61 upright microscope (Olympus; Tokyo, Japan). This system is equipped with GaAsP photomultiplier tubes and a tunable femtosecond laser (Spectra Physics, MaiTai DeepSee). The system is capable of providing multi-color imaging including second harmonic generation (SHG) imaging. Tissues designated for two-photon microscopy scans were mounted on chamber slides and immersed in PBS. Scans were performed with excitation at $980 \mathrm{~nm}$ and scanning from the surface to as deep as could be resolved at $5 \mu \mathrm{m}$ steps.

\subsection{Uni-axial Testing and Related Data Analyses of Collagen Sponges}

Dog bone shaped samples ( $8 \mathrm{~mm}$ wide that narrows to $4 \mathrm{~mm}$ wide in the middle, $25 \mathrm{~mm}$ long) were punched from the glutaraldehyde fixed CS for the mechanical tests. The samples were each incubated for 7 days at $37^{\circ} \mathrm{C}$ shaking 
at 110RPM in $5 \mathrm{ml}$ per sample of PBS or PBS with either: glucose $(100 \mathrm{mM})$, glyoxal $(50 \mathrm{mM}), \mathrm{BSA}(5 \%)$, glucose $(100 \mathrm{mM})+$ BSA $(5 \%)$, or glyoxal $(50 \mathrm{mM})+$ BSA $(5 \%)$. All incubations contained sodium azide $(0.1 \%)$ to maintain sterility. Samples were extensively rinsed with PBS and stored in PBS at $4{ }^{\circ} \mathrm{C}$ until the mechanical tests. Prior to testing, samples' cross-sectional area was calculated by measuring the cross-section's length and width using a micrometer. The mechanical testing consisted of: preloading to $0.03 \mathrm{~N}$ ( $\sim 3 \mathrm{x}$ the sample wet weight), 10 cycles at $1 \mathrm{~Hz}$ of preconditioning going from $0 \%$ to $10 \%$ strain, a relaxation test rapidly $(14 \mathrm{~mm} / \mathrm{s})$ extending to $20 \%$ strain and holding for $60 \mathrm{~s}$, a 2 -minute recovery period at 0 strain, then a slow extension $(0.05 \mathrm{~mm} / \mathrm{s})$ to failure. All mechanical testing was performed at the Penn Center for Musculoskeletal Disorders (University of Pennsylvania; Philadelphia, PA) on an Instron ${ }^{\circledR} 5542$ system (Instron; Norwood, MA). Load (N) and extension $(\mathrm{mm})$ measurements were recorded alongside images of samples following preloading. Samples that did not break cleanly in the center or that slipped during testing were excluded.

The time-load-extension data were analyzed using custom Matlab (Mathworks; Natick, MA) scripts to extract viscoelastic, linear elastic, and failure mechanical properties. Zero strain length was determined by pixel measurement of clamp to clamp distance following preloading. Viscoelastic metrics calculated were the degree of relaxation (the fraction of stress attenuation during relaxation, $1-\sigma_{\text {equilibrium }} / \sigma_{\text {peak }}$ ) and time constant of relaxation curve. Linear elastic metrics calculated were the elastic modulus (slope of the stress-strain curve in the linear loading region, expressed as $\mathrm{MPa}$ ) and the engineering strain at start of the linear loading region of the stressstrain curve. Failure metrics calculated were the ultimate tensile strength (the stress at mechanical failure, expressed as $\mathrm{MPa}$ ) and the engineering strain at failure. The mechanical data were normalized to the PBS incubation data for each repetition before comparisons.

\subsection{Statistical Methods}

The significance of the effects of BSA presence on 28-day glucose and glyoxal incorporation was determined by two-sample t-test (2.3.1). A two-sample t-test was also used to compare the 28-day incorporation of glucose and glyoxal on fresh and glutaraldehyde fixed bovine pericardium (2.3.2). It was also considered whether the assumptions of the t-test are warranted and the nonparametric analogue, Wilcoxon rank sum, was used instead. To evaluate the significance of the change in dry mass at 28 days, Dunnett's method was used to compare all BSA groups to the PBS control while Tukey's HSD test compared each BSA incubation to one another (2.3.3). Dunnett's method was also used to determine the significance of the changes from the PBS control for each of the metrics from the mechanical tests on the CS (2.6). For all statistical tests, $\mathrm{p}<0.05$ was considered significant. All data are expressed as mean \pm standard deviation. 


\section{$\underline{3.1 \text { Model glycation studies }}$}
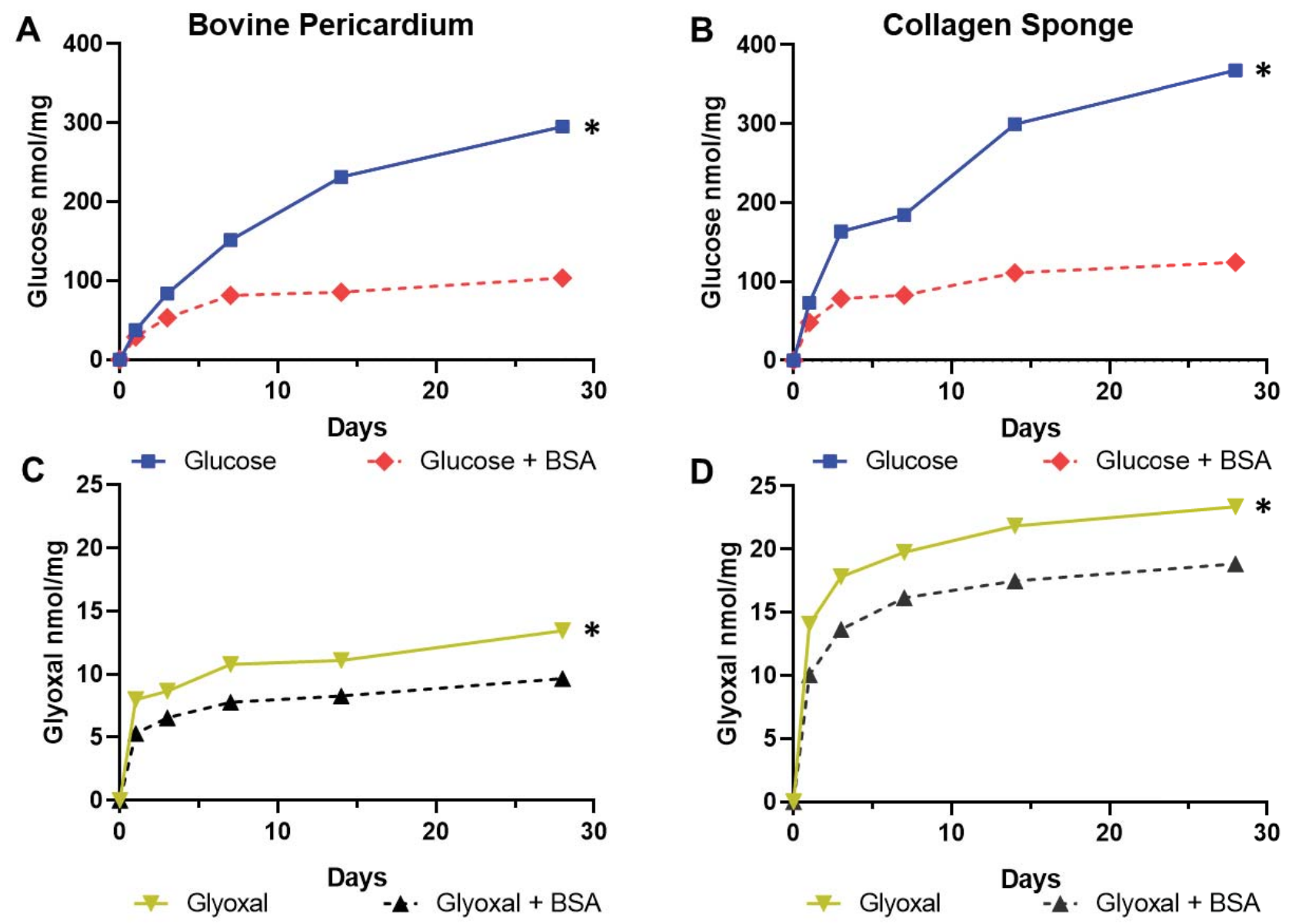

Figure 1. Glycation of glutaraldehyde pretreated bovine pericardium (BP) compared to glutaraldehyde pretreated collagen sponges $(\mathrm{CS})$ : ${ }^{14} \mathrm{C}$-glucose and ${ }^{14} \mathrm{C}$-glyoxal incorporation studies with and without the presence of bovine serum albumin (BSA) to simulate serum protein conditions.

A) ${ }^{14} \mathrm{C}$-glucose $(100 \mathrm{mM})$ uptake by BP with and without the presence of BSA $(5 \%) .{ }^{*} \mathrm{p}<0.001$

B) ${ }^{14} \mathrm{C}$-glucose $(100 \mathrm{mM})$ uptake by CS with and without the presence of BSA $(5 \%) .{ }^{*} \mathrm{p}<0.001$

C) ${ }^{14} \mathrm{C}$-glyoxal $(50 \mathrm{mM})$ uptake by BP with and without the presence of BSA (5\%). * $\mathrm{p}<0.001$

D) ${ }^{14} \mathrm{C}$-glyoxal $(50 \mathrm{mM})$ uptake by CS with and without the presence of BSA $(5 \%) .{ }^{*} \mathrm{p}<0.001$

Data shown are means of 10 replicates for $1 \mathrm{~A}$ and $1 \mathrm{C}$ and means of 5 replicates for $1 \mathrm{~B}$ and $1 \mathrm{D}$. The standard deviations of these values are too small to show graphically. Significance was determined by two sample t-tests.

These experiments sought to characterize the kinetics and extent of glucose and glyoxal incorporation into BP and CS in order to model AGE formation in these materials. BP was chosen for use in these experiments because of its use in BHV leaflets, and CS was investigated as a model collagenous material, hypothetically comparable to BP, and better suited for the mechanical studies presented later in this paper. The approach for these studies was to assess the overall potential for AGE formation using both ${ }^{14} \mathrm{C}$-glucose and ${ }^{14} \mathrm{C}$-glyoxal incorporation as exemplary glycation reagents. The rationale for these studies was based on established AGE formation reactions involving glyoxal, a reactive intermediary derived from glucose that specifically reacts with lysine and arginine residues[15]. Furthermore, glyoxal is involved in the formation of carboxy-methyl-lysine (CML), an AGE 
involved in the pathophysiology of diabetes and other diseases[24-26]. Serum proteins are AGE modified[24,27]; thus, their influence on ${ }^{14} \mathrm{C}$-glucose and ${ }^{14} \mathrm{C}$-glyoxal incorporation was modeled in these studies of BP and CS using serum albumin, the most abundant serum protein, at physiologic concentrations in the specific protocols.

Glucose incorporation, without BSA, was observed to reach $37.4 \pm 8.53 \mathrm{nmol} / \mathrm{mg}$ in BP at 24 hours (Figure 1A) and, by comparison, in CS the 24-hour incorporation was $73.26 \pm 2.27 \mathrm{nmol} / \mathrm{mg}$ (Figure 1B). Glucose incorporation leveled off at 7 days, and plateaued by 28 days reaching $295.19 \pm 22.84 \mathrm{nmol} / \mathrm{mg}$ in BP (Figure 1A) and $367.84 \pm 10.99 \mathrm{nmol} / \mathrm{mg}$ in CS (Figure 1B). Glucose incorporation in the presence of BSA had comparable kinetics to glucose alone: leveling off at 7 days and plateauing by 28 days in both BP and CS. Co-incubation with BSA resulted in glucose content of $28.96 \pm 2.12 \mathrm{nmol} / \mathrm{mg}$ in BP (Figure 1A) and $48.23 \pm 14.16 \mathrm{nmol} / \mathrm{mg}$ in CS at 24 hours (Figure 1B). After 28 days, glucose levels for the co-incubation with BSA reached $103.6 \pm 7.26$ $\mathrm{nmol} / \mathrm{mg}$ in BP (Figure 1A) and $124.38 \pm 3.68 \mathrm{nmol} / \mathrm{mg}$ in CS (Figure 1B).

Glyoxal incorporation at 24 hours was $7.98 \pm 1.54 \mathrm{nmol} / \mathrm{mg}$ in BP (Figure 1C) and, by comparison, the 24-hour incorporation in CS was $14.07 \pm 0.26 \mathrm{nmol} / \mathrm{mg}$ (Figure 1D). Glyoxal incorporation leveled off after 7 days and plateaued at 28 days in both BP and CS. Glyoxal incorporation at 28 days reached $13.45 \pm 1.77 \mathrm{nmol} / \mathrm{mg}$ in BP (Figure 1A) and $23.36 \pm 0.47 \mathrm{nmol} / \mathrm{mg}$ in CS (Figure 1D). Co-incubation with BSA resulted in $5.29 \pm 0.56$ $\mathrm{nmol} / \mathrm{mg}$ in BP (Figure 1C), and $10.04 \pm 0.15 \mathrm{nmol} / \mathrm{mg}$ in CS at 24 hours (Figure 1D). Glyoxal incorporation in the presence of BSA appeared to also level off by 7 days and plateau at 28 days in both BP and CS. The plateau levels reached at 28 days were $9.66 \pm 0.75 \mathrm{nmol} / \mathrm{mg}$ in BP (Figure 1C) and $18.84 \pm 0.31 \mathrm{nmol} / \mathrm{mg}$ in CS (Figure 1D).

\section{$\underline{3.2 \text { Glycation of bovine pericardium occurs regardless of glutaraldehyde pretreatment }}$}
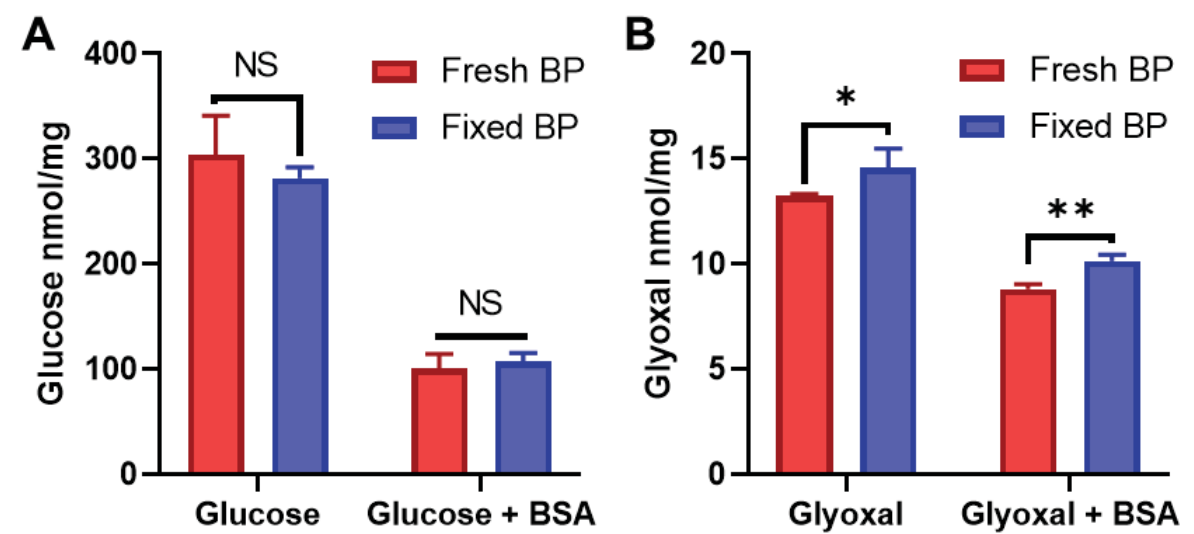

Figure 2. Glycation of non-crosslinked bovine pericardium (BP) compared to glycation of glutaraldehydecrosslinked BP: ${ }^{14} \mathrm{C}$-glucose and ${ }^{14} \mathrm{C}$-glyoxal incorporation studies.

A) ${ }^{14} \mathrm{C}$-glucose $(100 \mathrm{mM})$ incorporation into fresh or glutaraldehyde pretreated $\mathrm{BP}$, with or without co-incubation in BSA (5\%), was studied as above (Figure 1). No significant differences in incorporation due to glutaraldehyde pretreatment were noted (NS, not statistically significant).

B) ${ }^{14} \mathrm{C}$-glyoxal $(50 \mathrm{mM})$ incorporation with or without BSA $(5 \%)$ into fresh BP versus glutaraldehyde-fixed BP was also studied. Glutaraldehyde pretreated BP demonstrated a small but significant increase in glyoxal incorporation $(* \mathrm{p}=0.028, * * \mathrm{p}<0.001)$.

Data shown are 5 replicates. Error bars indicate standard deviation. Significance was determined by two sample ttests. 
Glutaraldehyde crosslinking is the universally used pre-treatment step for preparing bioprosthetic heart valves. However, the effects of glutaraldehyde pretreatment on AGE formation have not been previously studied. Glutaraldehyde reacts with primary amines, principally lysine, to form Schiff bases and heterocyclic crosslinks. This could hypothetically block glycation sites arising from lysyl amine reactions. To assess the effect glutaraldehyde-crosslinking has on glycation capacity, experiments were performed to compare ${ }^{14} \mathrm{C}$-glucose and ${ }^{14} \mathrm{C}$-glyoxal incorporation into fresh BP and glutaraldehyde-fixed BP.

Fresh BP 28-day glucose incorporation was $304.14 \pm 37.02 \mathrm{nmol} / \mathrm{mg}$ (Figure 2A). This was similar to the glutaraldehyde-fixed BP glucose incorporation of $281.85 \pm 10.27 \mathrm{nmol} / \mathrm{mg}$ by day 28 . In the co-incubation with BSA, glucose incorporation at 28 days was $100.86 \pm 13.80 \mathrm{nmol} / \mathrm{mg}$ into the fresh BP and $107.51 \pm 8.12 \mathrm{nmol} / \mathrm{mg}$ into the glutaraldehyde-fixed BP (Figure 2A). By 28 days, the glyoxal incorporation into the fresh BP was $13.25 \pm$ $0.10 \mathrm{nmol} / \mathrm{mg}$ (Figure 2B). The glyoxal incorporation into the glutaraldehyde-fixed BP was $14.59 \pm 0.90$ $\mathrm{nmol} / \mathrm{mg}$. In the glyoxal-BSA co-incubation, the 28 -day glyoxal incorporation was $8.80 \pm 0.23 \mathrm{nmol} / \mathrm{mg}$ into the fresh BP and $10.14 \pm 0.30 \mathrm{nmol} / \mathrm{mg}$ into the glutaraldehyde-fixed BP (Figure 2B).

\section{$\underline{3.3 \text { Model studies of BSA glycation }}$}

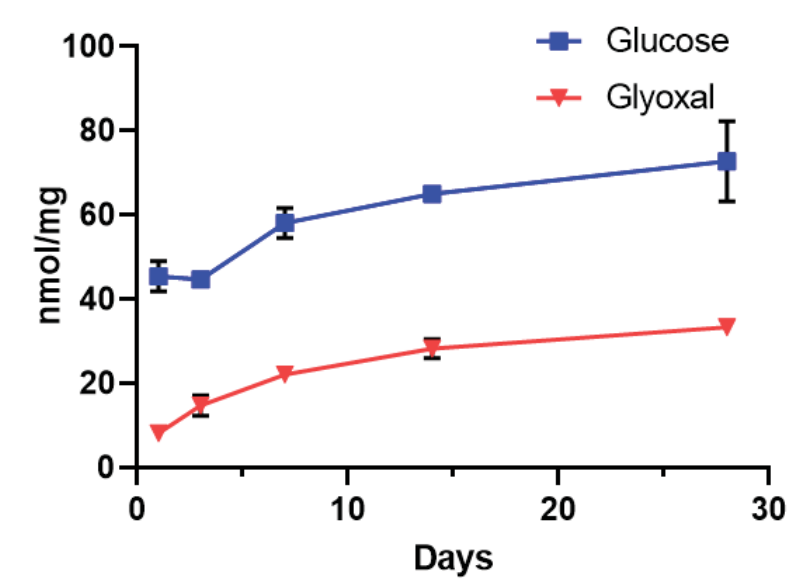

Figure 3. The kinetics of glycation of bovine serum albumin: ${ }^{14} \mathrm{C}$-glucose and ${ }^{14} \mathrm{C}$-glyoxal incorporation studies. The 28 -day time courses of ${ }^{14} \mathrm{C}$-glucose $(100 \mathrm{mM})$ or ${ }^{14} \mathrm{C}$-glyoxal $(50 \mathrm{mM})$ incorporation into $5 \%$ bovine serum albumin are shown. Data shown are 3 replicates. Error bars indicate standard deviations.

BSA co-incubations significantly altered the glycation levels of BP and CS (Figure 1); therefore, the following studies investigated the glycation kinetics of BSA. BSA was incubated in the presence of ${ }^{14} \mathrm{C}$-glucose or ${ }^{14} \mathrm{C}$ glyoxal with the resulting incorporation measured. Unlike the BP and CS glycation kinetics (Figure 1), the glycation of the BSA did not plateau by 28 days (Figure 3); both glucose and the glyoxal incorporation into BSA demonstrated comparable kinetics with increasing incorporation over the 28-day time course. Glucose incorporation into BSA was $45.45 \pm 3.59 \mathrm{nmol} / \mathrm{mg}$ at 24 hours and $72.78 \pm 9.49 \mathrm{nmol} / \mathrm{mg}$ at 28 days (Figure 3). Glyoxal incorporation into BSA was $8.24 \pm 0.84 \mathrm{nmol} / \mathrm{mg}$ at 24 hours and $33.38 \pm 0.33 \mathrm{nmol} / \mathrm{mg}$ at 28 days (Figure 3). Based on the concentrations of glucose and glyoxal, $3.64 \pm 0.47 \%$ of the glucose and $3.33 \pm 0.03 \%$ of the glyoxal are bound to the BSA by day 28 .

\section{$\underline{3.4 \text { Bovine serum albumin mass uptake by bovine pericardium }}$}




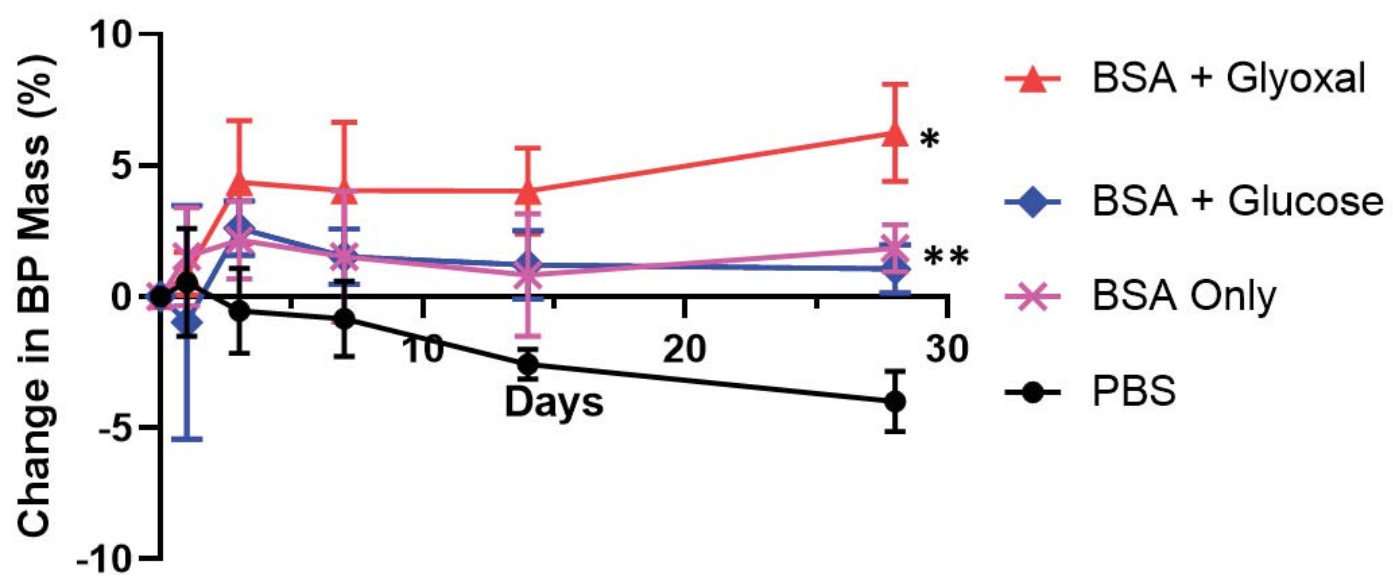

Figure 4. The changes in mass of glutaraldehyde-crosslinked bovine pericardial samples (BP) using glycation conditions in the presence of bovine serum albumin (BSA) to simulate serum protein exposure. Change in dry mass of BP samples over 28-day time course incubating in either: PBS (control), BSA (5\%), BSA $(5 \%)$ with glucose $(100 \mathrm{mM})$, or $5 \%$ BSA $(5 \%)$ with glyoxal $(50 \mathrm{mM})$. Data shown are percentages of the change in weight from the starting measures with 5 replicates for each condition. Error bars indicate standard deviation. ${ }^{*}$ Comparison by Dunnett's method showed BSA + glyoxal had significantly different mass change from PBS $(\mathrm{p}<0.001)$. Comparison using Tukey's HSD showed significant differences between BSA + glyoxal and both BSA $(\mathrm{p}<0.001)$ and BSA + glucose $(\mathrm{p}<0.001)$ at 28 days.

** Comparison by Dunnett's method showed BSA and BSA + glucose each had significant changes relative to PBS at 28 days $(\mathrm{p}<0.001)$. Comparison using Tukey's HSD test showed no significant difference between BSA and BSA + glucose at 28 days.

BP samples were incubated in BSA, BSA with glucose, and BSA with glyoxal to model BHV serum protein exposure under different glycation conditions with the resulting BP mass change quantitated. Albumin addition was quantified as the percent change in the dry (Figure 4) and wet weight (not shown) of BP samples from the dry and wet weight before a 1- to 28- day incubation. The dry weight data showed a $4.00 \pm 1.15 \%$ cumulative loss of mass in the PBS incubation by day 28 (Figure 4). Incubation in BSA offset this loss of dry weight, causing a net increase of $1.84 \pm 0.90 \%$ by day 28 (Figure 4). Glucose presence in the glucose-BSA co-incubation demonstrated no significant effect on the dry mass change relative to BSA by itself with a 28 -day mass increase of $1.06 \pm$ $0.91 \%$ (Figure 4). By contrast, glyoxal presence in the glyoxal-BSA co-incubation significantly increased the dry weight gain relative to both the PBS incubation and the BSA-only incubation, reaching a net increase of $6.24 \pm$ $1.85 \%$ after 28 days (Figure 4). The change in wet weight data was inconsistent, with too great a variance for statistically significant differences between treatments to be observed.

\section{$\underline{3.5 \text { Protein glycation as demonstrated by immunostaining of bovine pericardium }}$}


bioRxiv preprint doi: https://doi.org/10.1101/2020.05.28.117739; this version posted May 29, 2020. The copyright holder for this preprint (which was not certified by peer review) is the author/funder, who has granted bioRxiv a license to display the preprint in perpetuity. It is made available under aCC-BY-NC-ND 4.0 International license.

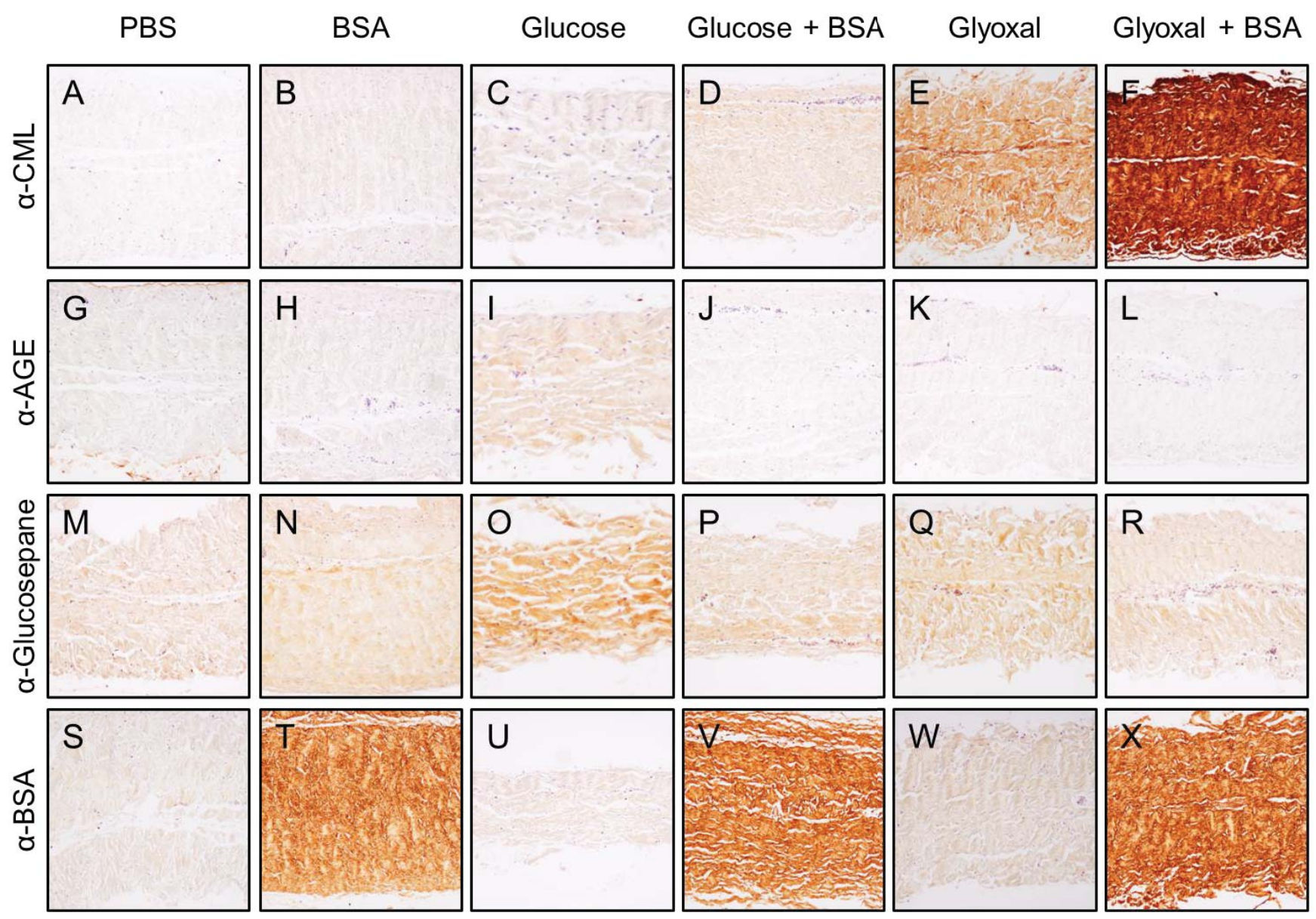

Figure 5. Formation of advanced glycation end products (AGE) in glutaraldehyde-crosslinked bovine pericardium following in vitro incubation: glycation-specific immunohistochemistry micrographs of glutaraldehyde-crosslinked bovine pericardium incubated for 28 days using the conditions indicated: A-F) Staining for carboxy-methyl-lysine (CML); G-L) Staining for general AGE formation. M-R); Staining for glucosepane formation. S-X); Staining for bovine serum albumin (BSA). Immunoperoxidase staining was used with a substrate of 3,3'Diaminobenzidine; Incubation concentrations were: bovine serum albumin (BSA, 5\%), glucose $(100 \mathrm{mM})$, and glyoxal $(50 \mathrm{mM})$.

Original magnification 100x.

These studies sought to characterize the morphologic distribution of protein glycation resulting from the incubation conditions described above. Glycation precursors, such as glucose and glyoxal, have a large family of intermediaries, including Amadori products, on the pathway to forming the mostly irreversible AGE[15]. The antibodies used in these experiments were specific for: CML, an AGE derived from glyoxal[15,24]; general AGE formation; and glucosepane, the most common physiological crosslinking AGE[28]. The BP samples were incubated for 28 days to correspond with the radioactive assays (Figure 1) and two-photon microscopy scans (Figure 6). The CS samples were incubated for 7 days to correspond with the mechanical tests (Table 1).

An array of representative micrographs of immunohistochemistry-stained incubated BP following a 28-day incubation are shown in Figure 5. The $\alpha$-CML antibody lead to moderate staining in the glyoxal incubated sample (Figure 5E) and heavy staining in the glyoxal-BSA co-incubated sample (Figure 5F) relative to the PBS control (Figure 5A). The $\alpha$-AGE antibody prompted increased staining only in the glucose incubated sample (Figure 5I) relative to the PBS control (Figure $5 \mathrm{G}$ ). Likewise, the $\alpha$-glucosepane antibody demonstrated increased staining 
bioRxiv preprint doi: https://doi.org/10.1101/2020.05.28.117739; this version posted May 29, 2020. The copyright holder for this preprint (which was not certified by peer review) is the author/funder, who has granted bioRxiv a license to display the preprint in perpetuity. It is made available under aCC-BY-NC-ND 4.0 International license.

over the PBS control only in the glucose incubated samples (Figure $5 \mathrm{O}$ vs 5M). The samples exposed a BSA incubation (Figure 5T, 5V and 5X) each showed significant staining with the $\alpha$-BSA antibody relative to the PBS control (Figure 5S) with the darkest staining occurring in samples from the glyoxal-BSA co-incubation (Figure $5 \mathrm{X})$.

\subsection{The effects of protein glycation on BP collagen structure- - two photon microscopy results}

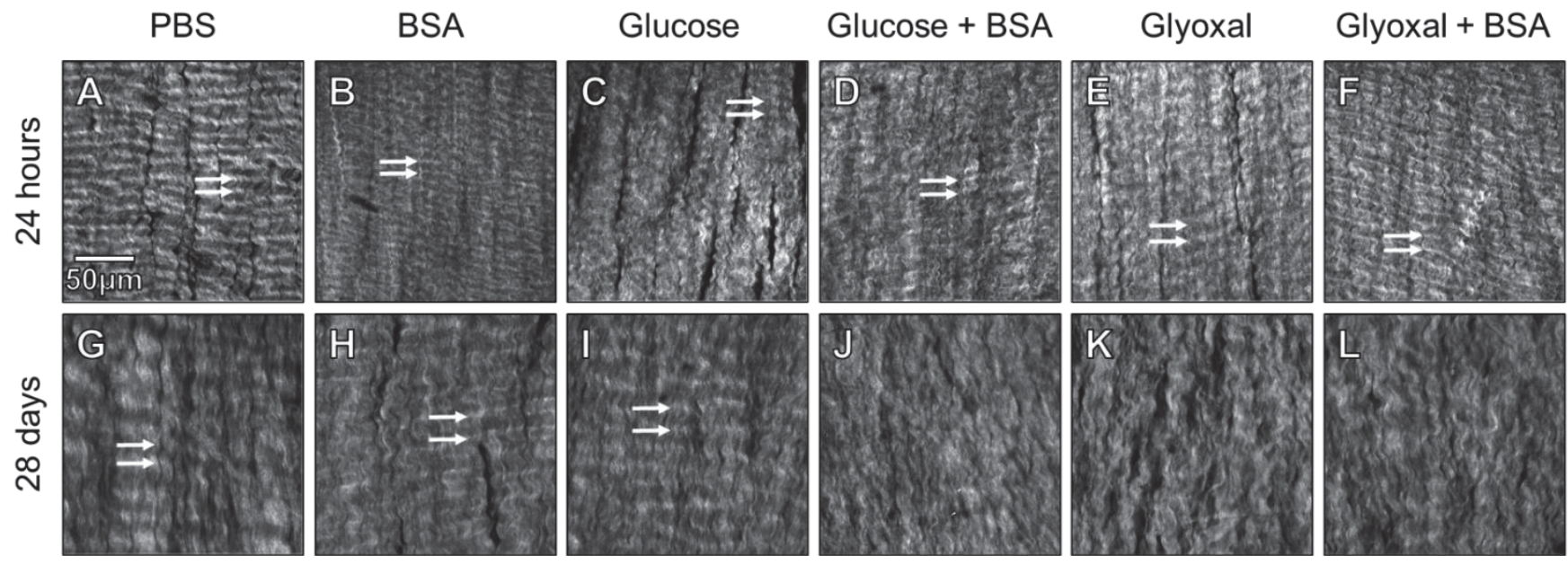

Figure 6. Two-photon microscopy images of glutaraldehyde-fixed bovine pericardium following in vitro incubations (see Methods): Samples were incubated for 24 hours (A-F) or 28 days (G-L) in the following media: A\&G) PBS, B\&H) bovine serum albumin (BSA, 5\%), C\&I) glucose (100mM), D\&J) glucose (100mM) plus BSA $(5 \%), \mathrm{E} \& \mathrm{~K})$ glyoxal $(50 \mathrm{mM})$, and $\mathrm{F} \& \mathrm{~L})$ glyoxal $(50 \mathrm{mM})$ plus BSA $(5 \%)$. All images are presented at the same scale. Arrows indicate typical crimp spacing where bands are discrete.

To study the effects of glycation and serum protein exposure on BHV's collagen microarchitecture, two-photon microscopy scans were performed on BP samples following in vitro incubations. BP samples after 24 hours of incubating consistently demonstrated collagen fibers were aligned with a tight crimp period and distinct crimping bands under all conditions (Figure 6A-F). Incubating BP in PBS for 4 weeks caused some alterations in the structure, but no significant loss of alignment nor a change in crimp period relative to 24 hours of PBS incubation (Figure 6G). After 4 weeks of BSA exposure, there is a significant loss of identifiable crimp and an increase in the crimp period relative to the image at 24 hours and 4 weeks of PBS, however, the fibers retain the bulk of the orientation and still have distinct crimp bands (Figure $6 \mathrm{H}$ ). Glucose exposure, by itself, had relatively mild effects that were similar to BSA exposure, some loss of crimp, a significant increase in crimp period relative to the 24 hours scans and 4 weeks of PBS exposure, but the BP retained collagen alignment and banding (Figure 6I). However, glucose-BSA co-incubation produced a dramatic disruption in the collagen microarchitecture, almost completely eliminating any crimp bands with significant collagen misalignment (Figure 6J). After 4 weeks of glyoxal exposure, the fibers are significantly maligned and the crimp bands are completely lost (Figure 6K). The glyoxal-BSA co-incubation produced the greatest modification of the structure after 4 weeks with compete loss of any crimp banding (Figure 6L).

\section{$\underline{3.7}$ The effects of glycation on the viscoelastic properties of collagen sponges}


A

A Relaxation
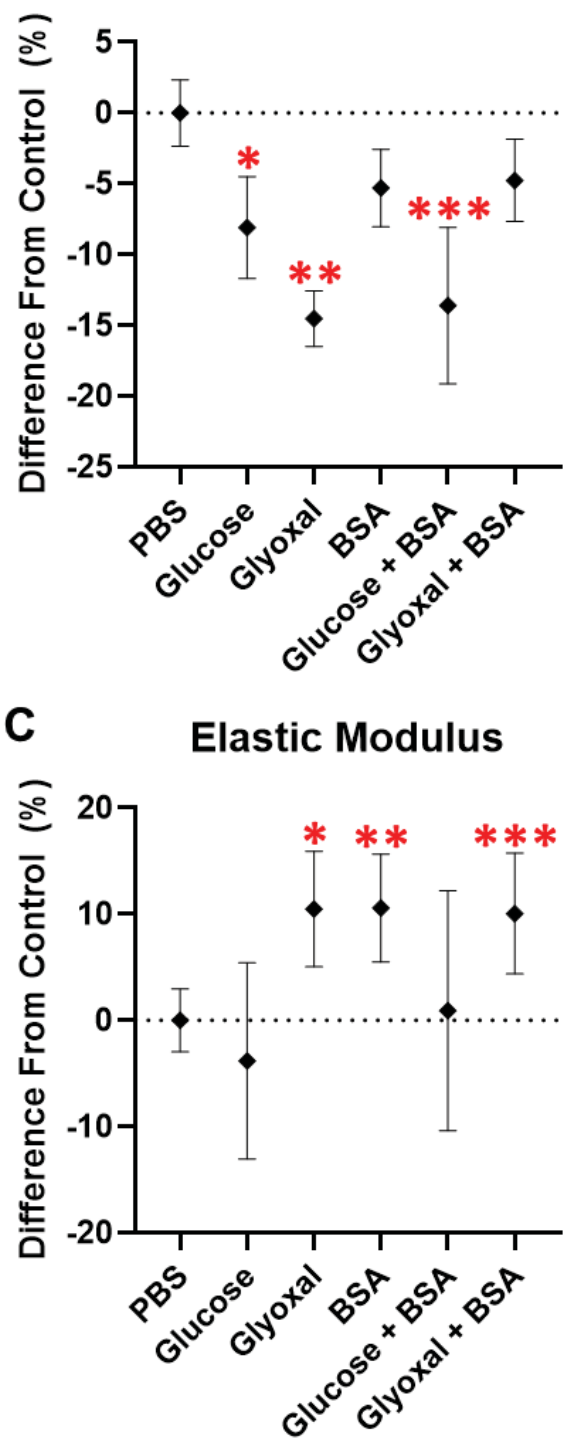

B
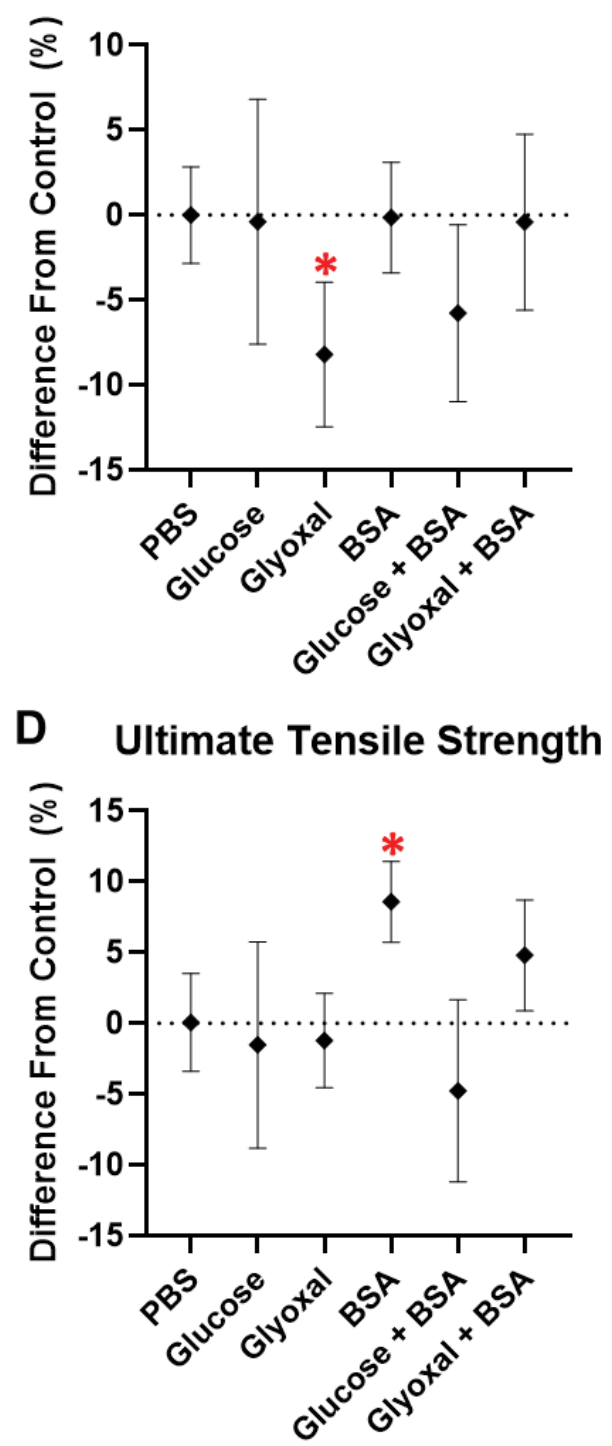

Figure 7. Changes of mechanical properties determined with uniaxial testing of collagen sponge samples following 7-day incubations. Results are normalized relative to phosphate buffered saline (PBS) controls.

A) Degree of relaxation, relative stress attenuation during relaxation. Significant decreases were observed with glucose $(* \mathrm{p}=0.0057)$, glyoxal $(* * \mathrm{p}<0.001)$, and glucose plus BSA $(* * * \mathrm{p}<0.001)$. B) Strain at mechanical failure. Significant decrease was observed with glyoxal $(* \mathrm{p}=0.026)$. C) Elastic modulus. Significant increases were observed with glyoxal $(* \mathrm{p}=0.030)$, BSA $(* * \mathrm{p}=0.010)$, and glyoxal plus BSA $(* * * \mathrm{p}=0.012)$. D) Ultimate tensile strength. Significant increase was observed with glyoxal $(* \mathrm{p}=0.004)$.

Incubation conditions were: PBS (control) [n=46], glucose $(100 \mathrm{mM})[\mathrm{n}=21]$, glyoxal $(50 \mathrm{mM})[\mathrm{n}=19]$, bovine serum albumin $(\mathrm{BSA}, 5 \%)[\mathrm{n}=38]$, glucose $(100 \mathrm{mM})$ plus BSA $(5 \%)[\mathrm{n}=16]$, and glyoxal $(50 \mathrm{mM})$ plus BSA $(5 \%)$ $[\mathrm{n}=36]$. Error bars indicate $95 \%$ confidence interval. Significance was determined by Dunnett's method comparing to PBS. 
To evaluate the effects glycation and serum proteins have on glutaraldehyde-fixed collagen's mechanics, uni-axial mechanical tests were performed on CS samples following 7-day in vitro incubation. CS was selected as there was no dominant directionality to the collagen fibers to complicate uni-axial tests. Furthermore, CS was found to have highly consistent and uniform mechanical and chemical properties in pilot studies. The 7-day duration was selected as glucose and glyoxal incorporation into the CS leveled off at 7 days (Figure 1B \& 1D). The mechanical tests consisted of a relaxation test, followed by a recovery period, then a slow extension to failure.

The effects of each treatment on the viscoelastic, linear elastic, and failure mechanical properties of the collagen sponges are expressed as changes from the PBS incubation (Figure 7). Glucose both by itself caused a significant loss in relaxation $(8.09 \pm 7.90 \%$, Figure $7 \mathrm{~A})$ with no significant changes in any other metric. Glyoxal exposure by itself produced a significant loss of relaxation $(14.51 \pm 4.08 \%$, Figure $7 \mathrm{~A})$, a significant decrease in the strain to reach failure $(8.20 \pm 10.51 \%$, Figure $7 \mathrm{~B})$, a significant increase in stiffness $(10.48 \pm 13.47 \%$, Figure $7 \mathrm{C})$. BSA by itself caused significant increase in elastic modulus $(10.57 \pm 15.42 \%$, Figure $7 \mathrm{C})$ and increase in ultimate tensile strength $(8.58 \pm 8.69 \%$, Figure $7 \mathrm{D})$. The glucose-BSA co-incubation was similar to glucose alone with the only significant change being a loss of relaxation (16.63 $\pm 9.99 \%$, Figure $7 \mathrm{~A})$. The glyoxal-BSA co-incubation had effects similar to the BSA-only incubation with a significant increase in stiffness $(10.05 \pm 18.23 \%$, Figure $7 \mathrm{C})$ and a marginal increase in ultimate tensile strength $(4.80 \pm 12.58 \%, p=0.22$, Figure $7 \mathrm{D})$ relative to the PBS control.

\section{DISCUSSION}

The present studies provide novel information concerning the susceptibility of BHV to glycation-related pathophysiology. Our results documented BHV glycation kinetics, processes by which glycation contributes to BHV SVD, and the deleterious effects of serum proteins that contribute to BHV glycation. These model system studies demonstrated that BHV are highly susceptible to rapid glycation (Figure 1) by both glucose and glyoxal, with or without serum albumin, and produced IHC results in BP in vitro comparable to failed clinical explants (Figure 5) [23]. Furthermore, the present studies show that AGE formation in BP occurs at sites independent of those involved in glutaraldehyde crosslinking, since fresh BP demonstrated comparable glucose and glyoxal incorporation as glutaraldehyde pretreated BP (Figure 2). These model studies used SHG to demonstrate disruption of collagen fibril organization (Figure 6) that was virtually identical to that seen in failed clinical explants[23]. Glucose effects modeled in vitro in the present studies, were not examined in our original report. However, glucose had a far greater level of incorporation than glyoxal (Figure 1A versus Figure 1C), and disrupted collagen structure (Figure 6) of BP with a morphology comparable to clinical explants[23]. It was also observed that there was significantly reduced glucose and glyoxal incorporation into BP and CS for the BSA coincubations (Figures 1\&2). The mechanisms responsible for this are complex, and the diminished glucose and glyoxal uptake were most likely due to BSA reactively binding to sites that would otherwise have reacted with glucose or glyoxal. BSA has a multitude of amino acids capable of engaging in the formation of AGE, including lysines, arginines and histidines. These BSA glycation-reactive amino acids are also involved in the formation of complex heterocyclic AGE as well as AGE-related crosslinks. Taken together this provides the basis for understanding our observation of the differential incorporation of glucose and glyoxal into BP and CS in the presence of BSA.

$\mathrm{CS}$, as a model for the BP collagen network, made possible uniaxial mechanical testing that documented alteration of the viscoelastic and linear elastic properties in CS due to AGE formation and serum protein incorporation (Figure 7). This means that through a cardiac cycle, the instantaneous load on glycated BHV tissue would be greater and the material would have less capacity to disperse the stress. These mechanical results provide a mechanistic explanation for our previous in vitro pulse duplicator findings that demonstrated AGE formation caused hydrodynamic dysfunction of clinical grade tricuspid BHV that resulted in decreased effective 
orifice area and increased pressure gradient[23]. These dysfunctional effects are directly related to clinical SVD. The present results suggest that the hydrodynamic changes observed in the pulse duplicator studies are likely due to increased stiffness and loss of viscoelasticity making the valve leaflets more resistant to cyclic opening.

The present results concerning the reaction kinetics of glucose and glyoxal with BP (Figure 1A\&C), while not previously reported in BHV studies, are comparable to previous model system results by others using radiolabeled glycation reagents [29-33]. For example, carboxymethyl lysine formation from ${ }^{14} \mathrm{C}$-glyoxal in bovine serum albumin has been shown in studies by others to have comparable reaction kinetics to those observed in our BHV investigations[30]. In addition, prior studies of ${ }^{14} \mathrm{C}$-glucose incorporation into retinal basement membranes [33] demonstrated reaction rate results that were also comparable to those for BP in our experiments. These comparisons indicate that the susceptibility of BHV to glycation occurs through mechanistic pathways that are operative in other pathophysiologies.

SHG analyses provided novel insights concerning collagen structural alterations in BP due to glycation and serum albumin uptake, such as collagen malalignment loss of collagen crimp (Figure 6). Collagen crimp, that structurally represents collagen's folding during its unloaded state, is important to BHV function and its loss causes is indicative of diminished compliance and increased susceptibility to mechanical injury[34]. This study's collagen modifications were comparable to the changes observed using SHG in our clinical study evaluating failed clinical BHV tissue, in vivo rat subdermal explanted BP, and in vitro pulse duplicator experiments[23]. Taken together these observations validate our current in vitro models as reproducing representative alterations in collagen structure, comparable to clinical explant BHV leaflets with SVD [23].

There are some caveats and limitations of this study to be noted. The concentrations of reagents used in the glycation studies were adjusted to provide an accelerated model system. An isotonic 5\% BSA solution was used. However, glyoxal was utilized at $50 \mathrm{mM}$, based on prior model studies using this reagent $[23,30,35,36]$, rather than the physiologic concentration $(\sim 154 \mathrm{nM})[37]$. Glucose, at $100 \mathrm{mM}$, was also used at diabetic level, hyperglycemic concentrations rather than physiologic $(\sim 5.6 \mathrm{mM})[38]$ levels. Nevertheless, this glucose concentration was representative of concentrations used in previous accelerated in vitro glycation studies by others[31-33,39-41]. Furthermore, glucose was not investigated in our prior AGE-BHV study of clinical explants[23], and is of strong relevance because of the more rapid SVD BHV failure process in diabetics[14]. Thus, the glucose results in the present results addressed the important contributions of glucose mediated glycation of BHV to SVD. The IHC assays of the study focused on well known, representative immunostaining targets reported in other glycation studies and these were: AGE, carboxymethyl lysine and glucosepane. These same IHC markers were endpoints in our clinical study[23] as well as other clinical studies[25,42-47], and thus have mechanistic and clinical relevance. Uniaxial testing of CS showed that glycation results in loss of viscoelasticity and increased stiffness (Figure 7). BP was not studied because of the well-known technical challenges of the anisotropic nature of $\mathrm{BP}[48-50]$. As discussed earlier, the present uniaxial testing observations account for the degeneration of the hydrodynamic properties of BHV following glycation and serum protein modifications observed in our pulse duplicator study[23].

The results of this study have several implications addressing SVD. AGE-mitigating strategies for use with BHV have not been previously investigated; the presents results indicate anti-AGE agents may be of interest. Currently available anti-AGE treatments include AGE inhibitors and AGE breakers. AGE inhibitors are pharmacologic agents, e.g. aminoguanidine and pyridoxamine, that prevent the formation of AGE by mechanisms such as scavenging the reactive carbonyl intermediates and blocking the oxidation of the Amadori intermediate, respectively[51]. AGE breakers, e.g. phenacyl-thiazolium bromide and alagebrium, function by cleaving glycation 
crosslinks and have been demonstrated to have the capacity to prevent or reverse glycation modifications in vascular disease[52,53]. The present study's model systems are capable of evaluating in vitro those treatments' efficacy at preventing or reversing the glycation modifications of BHV. Furthermore, our studies demonstrated the impact of serum protein infiltration in vitro on BHV structure and mechanical properties, and provided insights to explain clinical and experimental observations. Lastly, diabetic patients are at higher risk for earlier SVD $[14,54,55]$. Since the present studies showed significant effects of glucose on structure and mechanical properties of BP and CS, future in vivo model studies using diabetic animals represent an important direction. A notable example of such a study investigated both collagen and elastin scaffolds implanted subdermally in control and diabetic rats[56]. The samples explanted from diabetic rats demonstrated significantly increased biaxial stiffness compared to controls.

\section{CONCLUSIONS}

The results of the present study support the hypothesis that glycation and serum protein infiltration can contribute to SVD pathophysiology and lead to the following conclusions: 1) BP and CS are susceptible to rapidly progressive glycation and serum albumin incorporation; 2) BSA, with our without glyoxal or glucose, disrupts collagen structure; 3) Glucose alone, while not dramatically altering collagen structure after 28 days compared to PBS, does alter viscoelastic properties; 4) Similarly, collagen's uniaxial properties are significantly altered by both glycation and serum albumin incorporation. Taken together glycation and serum protein infiltration contribute to SVD via the structural changes in collagen that were observed in these studies and the related disruption of viscoelastic and linear elastic properties.

\section{Authorship contribution statement}

Christopher A. Rock: Conceptualization, Methodology, Software, Formal analysis, Investigation, Writing Original Draft, Project administration. Samuel Keeney: Methodology, Investigation, Writing - Original Draft, Writing - Review \& Editing. Andrey Zakharchenko: Methodology, Investigation, Writing - Original Draft.

Hajime Takano: Methodology, Software, Resources. David A. Spiegel: Resources. Abba M. Krieger: Formal analysis. Giovanni Ferrari: Conceptualization, Resources, Supervision, Funding acquisition. Robert J. Levy: Conceptualization, Methodology, Resources, Writing - Review \& Editing, Supervision, Funding acquisition.

Disclosure: Robert J. Levy is a consultant for WL Gore. This does not represent a conflict of interest related to this publication. David A. Spiegel is a shareholder of Revel Pharmaceuticals, and this does not represent a conflict of interest for the present studies. Christopher A. Rock, Samuel Keeney, Andrey Zakharchenko, Hajime Takano, Abba M. Krieger, and Giovanni Ferrari have no competing interests to disclose.

\section{ACKNOWLEDGEMENTS}

Biomechanical testing was performed at the Penn Center for Musculoskeletal Disorders (NIH AR069619). This work was supported by NIH R01s HL122805 (GF) and HL143008 (RJL and GF), T32s HL007915 (RJL and CR), HL007854 (APK) and HL007343 (AF), The Kibel Fund for Aortic Valve Research (to GF and RJL), The Valley Hospital Foundation 'Marjorie C Bunnel' charitable fund (to GF and JG), the American Diabetes Association Pathway to Stop Diabetes Grant 1-17-VSN-04 and the SENS Research Foundation (to DAS), and both Erin's Fund and the William J Rashkind Endowment of the Children's Hospital of Philadelphia (to RJL).

\section{TABLE OF ABBREVIATIONS}

AGE advanced glycation endproducts

BHV bioprosthetic heart valves

BP bovine pericardium 
BSA

bovine serum albumin

CML carboxy-methyl-lysine

CS collagen sponge

IHC immunohistochemistry

PBS

SHG phosphate buffered saline

SVD second harmonic generation structural valve degeneration

\section{REFERENCES}

[1] E.J. Benjamin, P. Muntner, A. Alonso, M.S. Bittencourt, C.W. Callaway, A.P. Carson, A.M. Chamberlain, A.R. Chang, S. Cheng, S.R. Das, F.N. Delling, L. Djousse, M.S.V. Elkind, J.F. Ferguson, M. Fornage, L.C. Jordan, S.S. Khan, B.M. Kissela, K.L. Knutson, T.W. Kwan, D.T. Lackland, T.T. Lewis, J.H. Lichtman, C.T. Longenecker, M.S. Loop, P.L. Lutsey, S.S. Martin, K. Matsushita, A.E. Moran, M.E. Mussolino, M. O’Flaherty, A. Pandey, A.M. Perak, W.D. Rosamond, G.A. Roth, U.K.A. Sampson, G.M. Satou, E.B. Schroeder, S.H. Shah, N.L. Spartano, A. Stokes, D.L. Tirschwell, C.W. Tsao, M.P. Turakhia, L.B. VanWagner, J.T. Wilkins, S.S. Wong, S.S. Virani, Heart Disease and Stroke Statistics-2019 Update: A Report From the American Heart Association, Circulation. 139 (2019) e56-e528. https://doi.org/10.1161/CIR.0000000000000659.

[2] A.P. Carnicelli, P.T. O'Gara, R.P. Giugliano, Anticoagulation After Heart Valve Replacement or Transcatheter Valve Implantation, Am. J. Cardiol. $118 \quad$ (2016) 1419-1426. https://doi.org/10.1016/j.amjcard.2016.07.048.

[3] D. Dvir, T. Bourguignon, C.M. Otto, R.T. Hahn, R. Rosenhek, J.G. Webb, H. Treede, M.E. Sarano, T. Feldman, H.C. Wijeysundera, Y. Topilsky, M. Aupart, M.J. Reardon, G.B. Mackensen, W.Y. Szeto, R. Kornowski, J.S. Gammie, A.P. Yoganathan, Y. Arbel, M.A. Borger, M. Simonato, M. Reisman, R.R. Makkar, A. Abizaid, J.M. McCabe, G. Dahle, G.S. Aldea, J. Leipsic, P. Pibarot, N.E. Moat, M.J. Mack, A.P. Kappetein, M.B. Leon, Standardized Definition of Structural Valve Degeneration for Surgical and Transcatheter Bioprosthetic Aortic Valves, Circulation. $137 \quad$ (2018) 388-399. https://doi.org/10.1161/CIRCULATIONAHA.117.030729.

[4] T. Rodriguez-Gabella, P. Voisine, R. Puri, P. Pibarot, J. Rodés-Cabau, Aortic Bioprosthetic Valve Durability: Incidence, Mechanisms, Predictors, and Management of Surgical and Transcatheter Valve Degeneration, J. Am. Coll. Cardiol. 70 (2017) 1013-1028. https://doi.org/10.1016/j.jacc.2017.07.715.

[5] N. Vyavahare, D. Hirsch, E. Lerner, J.Z. Baskin, F.J. Schoen, R. Bianco, H.S. Kruth, R. Zand, R.J. Levy, Prevention of bioprosthetic heart valve calcification by ethanol preincubation: Efficacy and mechanisms, Circulation. 95 (1997) 479-488. https://doi.org/10.1161/01.CIR.95.2.479.

[6] F.J. Schoen, J.W. Tsao, R.J. Levy, Calcification of bovine pericardium used in cardiac valve bioprostheses. Implications for the mechanisms of bioprosthetic tissue mineralization., Am. J. Pathol. 123 (1986)

$134-45$. http://www.pubmedcentral.nih.gov/articlerender.fcgi?artid=1888152\&tool=pmcentrez\&rendertype=abstra ct.

[7] R.S. Farivar, L.H. Cohn, D.C. Miller, Hypercholesterolemia is a risk factor for bioprosthetic valve calcification and explantation, J. Thorac. Cardiovasc. Surg. $126 \quad$ (2003) 969-976. https://doi.org/10.1016/S0022-5223(03)00708-6.

[8] S. Lee, D.H. Kim, Y.N. Youn, H.C. Joo, K.J. Yoo, S.H. Lee, Rosuvastatin attenuates bioprosthetic heart valve calcification, J. Thorac. Cardiovasc. Surg. $158 \quad$ (2019) 731-741.e1. https://doi.org/10.1016/j.jtcvs.2018.12.042. 
[9] H. Scott Rapoport, J.M. Connolly, J. Fulmer, N. Dai, B.H. Murti, R.C. Gorman, J.H. Gorman, I. Alferiev, R.J. Levy, Mechanisms of the in vivo inhibition of calcification of bioprosthetic porcine aortic valve cusps and aortic wall with triglycidylamine/mercapto bisphosphonate, Biomaterials. 28 (2007) 690-699. https://doi.org/10.1016/j.biomaterials.2006.09.029.

[10] R.S. McClure, N. Narayanasamy, E. Wiegerinck, S. Lipsitz, A. Maloney, J.G. Byrne, S.F. Aranki, G.S. Couper, L.H. Cohn, Late Outcomes for Aortic Valve Replacement With the Carpentier-Edwards Pericardial Bioprosthesis: Up to 17-Year Follow-Up in 1,000 Patients, Ann. Thorac. Surg. 89 (2010) 1410-1416. https://doi.org/10.1016/j.athoracsur.2010.01.046.

[11] P.H. Neville, M.R. Aupart, F.F. Diemont, A.L. Sirinelli, E.M. Lemoine, M.A. Marchand, CarpentierEdwards pericardial bioprosthesis in aortic or mitral position: a 12-year experience, Ann. Thorac. Surg. 66 (1998) S143-S147. https://doi.org/10.1016/S0003-4975(98)01122-9.

[12] T. Bourguignon, A.-L. Bouquiaux-Stablo, P. Candolfi, A. Mirza, C. Loardi, M.-A. May, R. El-Khoury, M. Marchand, M. Aupart, Very Long-Term Outcomes of the Carpentier-Edwards Perimount Valve in Aortic Position, Ann. Thorac. Surg. 99 (2015) 831-837. https://doi.org/10.1016/j.athoracsur.2014.09.030.

[13] J. Forcillo, M. Pellerin, L.P. Perrault, R. Cartier, D. Bouchard, P. Demers, M. Carrier, Carpentier-Edwards Pericardial Valve in the Aortic Position: 25-Years Experience, Ann. Thorac. Surg. 96 (2013) 486-493. https://doi.org/10.1016/j.athoracsur.2013.03.032.

[14] S. Lee, R.J. Levy, A.J. Christian, S.L. Hazen, N.E. Frick, E.K. Lai, J.B. Grau, J.E. Bavaria, G. Ferrari, Calcification and oxidative modifications are associated with progressive bioprosthetic heart valve dysfunction, J. Am. Heart Assoc. 6 (2017) 1-13. https://doi.org/10.1161/JAHA.117.005648.

[15] G. Vistoli, D. De Maddis, A. Cipak, N. Zarkovic, M. Carini, G. Aldini, Advanced glycoxidation and lipoxidation end products (AGEs and ALEs): an overview of their mechanisms of formation., Free Radic. Res. 47 Supp. 1 (2013) 3-27. https://doi.org/10.3109/10715762.2013.815348.

[16] R. Singh, A. Barden, T. Mori, L. Beilin, Advanced glycation end-products: A review, Diabetologia. 44 (2001) 129-146. https://doi.org/10.1007/s001250051591.

[17] G. Basta, A.M. Schmidt, R. De Caterina, Advanced glycation end products and vascular inflammation: Implications for accelerated atherosclerosis in diabetes, Cardiovasc. Res. 63 (2004) 582-592. https://doi.org/10.1016/j.cardiores.2004.05.001.

[18] M. Peppa, J. Uribarri, H. Vlassara, Glucose, Advanced Glycation End Products, and Diabetes Complications: What Is New and What Works, Clin. Diabetes. 21 (2003) 186-187. https://doi.org/10.2337/diaclin.21.4.186.

[19] S.Y. Rhee, Y.S. Kim, The role of advanced glycation end products in diabetic vascular complications, Diabetes Metab. J. 42 (2018) 188. https://doi.org/10.4093/dmj.2017.0105.

[20] H. Vicente Miranda, O.M.A. El-Agnaf, T.F. Outeiro, Glycation in Parkinson's disease and Alzheimer's disease, Mov. Disord. 31 (2016). https://doi.org/10.1002/mds.26566.

[21] S.Y. Ko, H.A. Ko, K.H. Chu, T.M. Shieh, T.C. Chi, H.I. Chen, W.C. Chang, S.S. Chang, The possible mechanism of advanced glycation end products (AGEs) for Alzheimer's disease, PLoS One. 10 (2015). https://doi.org/10.1371/journal.pone.0143345.

[22] V. Srikanth, A. Maczurek, T. Phan, M. Steele, B. Westcott, D. Juskiw, G. M??nch, G. Münch, Advanced glycation endproducts and their receptor RAGE in Alzheimer's disease, Neurobiol. Aging. 32 (2011) 763777. https://doi.org/10.1016/j.neurobiolaging.2009.04.016.

[23] A. Frasca, Y. Xue, A.P. Kossar, S. Keeney, C. Rock, A. Zakharchenko, M. Streeter, R.C. Gorman, J.B. 
bioRxiv preprint doi: https://doi.org/10.1101/2020.05.28.117739; this version posted May 29, 2020. The copyright holder for this preprint (which was not certified by peer review) is the author/funder, who has granted bioRxiv a license to display the preprint in perpetuity. It is made available under aCC-BY-NC-ND 4.0 International license.

Grau, I. George, J.E. Bavaria, A. Krieger, D.A. Spiegel, R.J. Levy, G. Ferrari, Glycation and Serum Albumin Infiltration Contribute to the Structural Degeneration of Bioprosthetic Heart Valves, BioRxiv. (2020) 2020.02.14.948075. https://doi.org/10.1101/2020.02.14.948075.

[24] K.J. Wells-Knecht, D. V Zyzak, J.E. Litchfield, S.R. Thorpe, J.W. Baynes, Identification of Glyoxal and Arabinose as Intermediates in the Autoxidative Modification of Proteins by Glucose, Biochemistry. 34 (1995) 3702-3709. https://doi.org/10.1021/bi00011a027.

[25] R.D. Semba, K. Sun, A. V. Schwartz, R. Varadhan, T.B. Harris, S. Satterfield, M. Garcia, L. Ferrucci, A.B. Newman, Serum carboxymethyl-lysine, an advanced glycation end product, is associatedwith arterial stiffness in older adults, J. Hypertens. 33 (2015) 797-803. https://doi.org/10.1097/HJH.0000000000000460.

[26] E.D. Schleicher, E. Wagner, A.G. Nerlich, Increased accumulation of the glycoxidation product N( $(\varepsilon)$ (carboxymethyl)lysine in human tissues in diabetes and aging, J. Clin. Invest. 99 (1997) 457-468. https://doi.org/10.1172/JCI119180.

[27] L. Kennedy, T.D. Mehl, E. Elder, M. Varghese, T.J. Merimee, Nonenzymatic Glycosylation of Serum and Plasma Proteins, Diabetes. 31 (1982) 52 LP - 56. https://doi.org/10.2337/diab.31.3.S52.

[28] D.R. Sell, K.M. Biemel, O. Reihl, M.O. Lederer, C.M. Strauch, V.M. Monnier, Glucosepane is a major protein cross-link of the senescent human extracellular matrix: Relationship with diabetes, J. Biol. Chem. 280 (2005) 12310. https://doi.org/10.1074/jbc.M500733200.

[29] S.M. Shaw, M.J.C. Crabbe, Monitoring the progress of non- enzymatic glycation in vitro, Int. J. Pept. Protein Res. 44 (1994) 594-602. https://doi.org/10.1111/j.1399-3011.1994.tb01149.x.

[30] M.A. Glomb, V.M. Monnier, Mechanism of Protein Modification by Glyoxal and Glycolaldehyde, Reactive Intermediates of the Maillard Reaction, J. Biol. Chem. . 270 (1995) 10017-10026. https://doi.org/10.1074/jbc.270.17.10017.

[31] S. Rogozinski, O.O. Blumenfeld, S. Seifter, The nonenzymatic glycosylation of collagen, Arch. Biochem. Biophys. 221 (1983) 428-437. https://doi.org/10.1016/0003-9861(83)90161-3.

[32] E. Schleicher, O.H. Wieland, Kinetic analysis of glycation as a tool for assessing the half-life of proteins, BBA - Gen. Subj. 884 (1986) 199-205. https://doi.org/10.1016/0304-4165(86)90244-8.

[33] W. Li, M. Khatami, G.A. Robertson, S. Shen, J.H. Rockey, Nonenzymatic glycosylation of bovine retinal microvessel basement membranes in vitro. Kinetic analysis and inhibition by aspirin, Investig. Ophthalmol. Vis. Sci. 25 (1984) 884-892.

[34] S.L. Hilbert, L.C. Sword, K.F. Batchelder, M.K. Barrick, V.J. Ferrans, Simultaneous assessment of bioprosthetic heart valve biomechanical properties and collagen crimp length, J. Biomed. Mater. Res. 31 (1996) 503-509. https://doi.org/10.1002/(SICI)1097-4636(199608)31:4<503::AID-JBM10>3.0.CO;2-H.

[35] P.K. Pampati, S. Suravajjala, J.A. Dain, Monitoring nonenzymatic glycation of human immunoglobulin G by methylglyoxal and glyoxal: A spectroscopic study, Anal. Biochem. 408 (2011) 59-63. https://doi.org/10.1016/j.ab.2010.08.038.

[36] Y. Li, M.A. Cohenford, U. Dutta, J.A. Dain, The structural modification of DNA nucleosides by nonenzymatic glycation: an in vitro study based on the reactions of glyoxal and methylglyoxal with $2^{\prime}$ deoxyguanosine, Anal. Bioanal. Chem. 390 (2008) 679-688. https://doi.org/10.1007/s00216-007-1682-4.

[37] K. Dhananjayan, F. Irrgang, R. Raju, D.G. Harman, C. Moran, V. Srikanth, G. Münch, Determination of glyoxal and methylglyoxal in serum by UHPLC coupled with fluorescence detection, Anal. Biochem. 573 (2019) 51-66. https://doi.org/10.1016/j.ab.2019.02.014. 
[38] Classification and diagnosis of diabetes: Standards of medical care in Diabetes-2018, Diabetes Care. 41 (2018) S13-S27. https://doi.org/10.2337/dc18-S002.

[39] D.A. Slatter, N.C. Avery, A.J. Bailey, Collagen in its fibrillar state is protected from glycation, Int. J. Biochem. Cell Biol. 40 (2008) 2253-2263. https://doi.org/10.1016/j.biocel.2008.03.006.

[40] D. Cervantes-Laurean, D.D. Schramm, E.L. Jacobson, I. Halaweish, G.G. Bruckner, G.A. Boissonneault, Inhibition of advanced glycation end product formation on collagen by rutin and its metabolites, J. Nutr. Biochem. 17 (2006) 531-540. https://doi.org/10.1016/j.jnutbio.2005.10.002.

[41] M. Francis-Sedlak, S. Uriel, J. Larson, H. Greisler, D. Venerus, E. Brey, Characterization of type I collagen gels modified by glycation, Biomaterials. 30 (2009) 1851-1856. https://doi.org/10.1016/j.biomaterials.2008.12.014.

[42] V.M. Monnier, D.R. Sell, C. Strauch, W. Sun, J.M. Lachin, P.A. Cleary, S. Genuth, The association between skin collagen glucosepane and past progression of microvascular and neuropathic complications in type 1 diabetes, J. Diabetes Complications. 27 (2013) 141-149. https://doi.org/10.1016/j.jdiacomp.2012.10.004.

[43] K.M. Bieme, D. Alexander Fried, M.O. Lederer, Identification and quantification of major maillard crosslinks in human serum albumin and lens protein: Evidence for glucosepane as the dominant compound, J. Biol. Chem. 277 (2002) 24907-24915. https://doi.org/10.1074/jbc.M202681200.

[44] S. Genuth, W. Sun, P. Cleary, X. Gao, D.R. Sell, J. Lachin, V.M. Monnier, Skin advanced glycation end products glucosepane and methylglyoxal hydroimidazolone are independently associated with long-Term microvascular complication progression of type 1 diabetes, Diabetes. 64 (2015) 266-278. https://doi.org/10.2337/db14-0215.

[45] H. Khan, M.S. Khan, S. Ahmad, The in vivo and in vitro approaches for establishing a link between advanced glycation end products and lung cancer, J. Cell. Biochem. 119 (2018). https://doi.org/10.1002/jcb.27170.

[46] M.K. Halushka, E. Selvin, J. Lu, A.M. Macgregor, T.C. Cornish, Use of human vascular tissue microarrays for measurement of advanced glycation endproducts, J. Histochem. Cytochem. 57 (2009) 559-566. https://doi.org/10.1369/jhc.2009.953273.

[47] S. Sakellariou, P. Fragkou, G. Levidou, A.N. Gargalionis, C. Piperi, G. Dalagiorgou, C. Adamopoulos, A. Saetta, G. Agrogiannis, I. Theohari, S. Sougioultzis, P. Tsioli, I. Karavokyros, N. Tsavaris, I.D. Kostakis, A. Zizi-Serbetzoglou, G.P. Vandoros, E. Patsouris, P. Korkolopoulou, Clinical significance of AGERAGE axis in colorectal cancer: Associations with glyoxalase-I, adiponectin receptor expression and prognosis, BMC Cancer. 16 (2016) 174. https://doi.org/10.1186/s12885-016-2213-5.

[48] E.D. Hiester, M.S. Sacks, Optimal bovine pericardial tissue selection sites. I. Fiber architecture and tissue thickness measurements, J. Biomed. Mater. Res. 39 (1998) 207-214. https://doi.org/10.1002/(SICI)10974636(199802)39:2<207::AID-JBM6>3.0.CO;2-T.

[49] A. Whelan, J. Duffy, R.T. Gaul, D. O’Reilly, D.R. Nolan, P. Gunning, C. Lally, B.. . Murphy, Collagen fibre orientation and dispersion govern ultimate tensile strength, stiffness and the fatigue performance of bovine pericardium, J. Mech. Behav. Biomed. Mater. 90 (2019) 54-60. https://doi.org/https://doi.org/10.1016/j.jmbbm.2018.09.038.

[50] H. Tam, W. Zhang, D. Infante, N. Parchment, M. Sacks, N. Vyavahare, Fixation of Bovine PericardiumBased Tissue Biomaterial with Irreversible Chemistry Improves Biochemical and Biomechanical Properties, J. Cardiovasc. Transl. Res. 10 (2017) 194-205. https://doi.org/10.1007/s12265-017-9733-5.

[51] R. Nagai, D.B. Murray, T.O. Metz, J.W. Baynes, Chelation: A fundamental mechanism of action of AGE 
bioRxiv preprint doi: https://doi.org/10.1101/2020.05.28.117739; this version posted May 29, 2020. The copyright holder for this preprint (which

was not certified by peer review) is the author/funder, who has granted bioRxiv a license to display the preprint in perpetuity. It is made available under aCC-BY-NC-ND 4.0 International license.

inhibitors, AGE breakers, and other inhibitors of diabetes complications, Diabetes. 61 (2012) 549-559. https://doi.org/10.2337/db11-1120.

[52] M.T. Coughlan, J.M. Forbes, M.E. Cooper, Role of the AGE crosslink breaker, alagebrium, as a renoprotective agent in diabetes, Kidney Int. 72 (2007) S54-S60. https://doi.org/10.1038/sj.ki.5002387.

[53] M.E. Cooper, V. Thallas, J. Forbes, E. Scalbert, S. Sastra, I. Darby, T. Soulis, The cross-link breaker, Nphenacylthiazolium bromide prevents vascular advanced glycation end-product accumulation, Diabetologia. 44 (2000) 660-664. https://doi.org/10.1007/s001250051355.

[54] R. Lorusso, S. Gelsomino, F. Lucà, G. De Cicco, G. Billè, R. Carella, E. Villa, G. Troise, M. Vigaǹ, C. Banfi, C. Gazzaruso, P. Gagliardotto, L. Menicanti, F. Formica, G. Paolini, S. Benussi, O. Alfieri, M. Pastore, S. Ferrarese, G. Mariscalco, G. Di Credico, C. Leva, C. Russo, A. Cannata, R. Trevisan, U. Livi, R. Scrofani, C. Antona, A. Sala, G.F. Gensini, J. Maessen, A. Giustina, Type 2 diabetes mellitus is associated with faster degeneration of bioprosthetic valve: results from a propensity score-matched Italian $\begin{array}{llllll}\text { multicenter } & \text { study., } & \text { Circulation. } & 125 & \text { (2012) }\end{array}$ https://doi.org/10.1161/CIRCULATIONAHA.111.025064.

[55] G. Nollert, J. Miksch, E. Kreuzer, B. Reichart, Risk factors for atherosclerosis and the degeneration of pericardial valves after aortic valve replacement, J. Thorac. Cardiovasc. Surg. 126 (2003) 965-968. https://doi.org/10.1016/S0022-5223(02)73619-2.

[56] J.P. Chow, D.T. Simionescu, H. Warner, B. Wang, S.S. Patnaik, J. Liao, A. Simionescu, Mitigation of diabetes-related complications in implanted collagen and elastin scaffolds using matrix-binding polyphenol, Biomaterials. 34 (2013) 685-695. https://doi.org/10.1016/j.biomaterials.2012.09.081. 


\section{Rock et al: Declaration of Interests Statement}

The following competing interests are disclosed: Robert J. Levy is a consultant for WL Gore. This does not represent a conflict of interest related to this publication. David A. Spiegel is a shareholder of Revel Pharmaceuticals. However, this does not constitute a conflict of interest concerning the present manuscript and its contents. Christopher A. Rock, Samuel Keeney, Andrey Zakharchenko, Hajime Takano, Abba M. Krieger, and Giovanni Ferrari have no competing interests to disclose. 


\section{Disrupted Collagen Structure}

\section{Pre-implant}

Bioprosthetic Valve

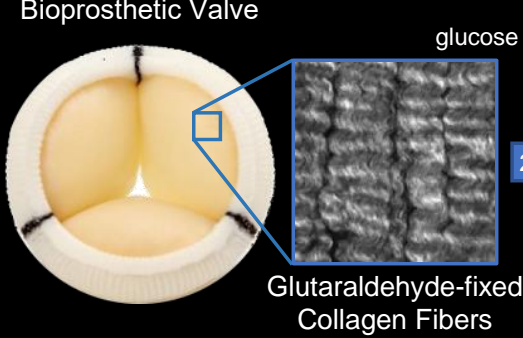

Glycation Precursors

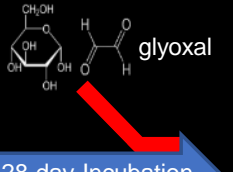

28-day Incubation

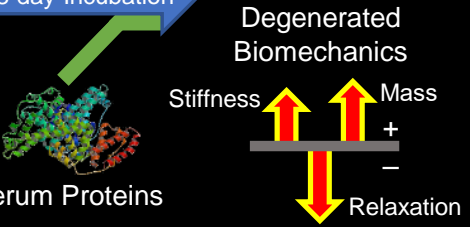

Explanted Bioprosthesis with Structural Degeneration 